\title{
Big Five Personality Types \& Knowledge Hiding Behaviour: A Theoretical Framework
}

\author{
Payal Anand \\ Indian Institute of Management Indore \\ f12payal@iimidr.ac.in \\ Kamal Kishore Jain \\ Indian Institute of Management Indore \\ kamal@iimidr.ac.in
}

\begin{abstract}
The paper provides a theoretical framework explaining the relationship between personality types and knowledge hiding behavior. In a knowledge based economy, knowledge is the foundation of a firm's competitive advantage. Capturing, storing, sharing, and using knowledge has gradually become an integral part of most firms' knowledge management strategy. Extensive knowledge sharing within organizations still appears to be the exception rather than the rule. Hoarding knowledge and looking guardedly at the knowledge offered by others are natural human tendencies (Davenport $\&$ Prusak, 1998). So far, there have been studies on knowledge sharing but knowledge hiding is the area which is still untapped. Moreover, no study has been done to study the relationship between personality types and knowledge hiding behavior. This study, therefore, attempts to fill that research gap by providing a theoretical framework based on literature review. The study uses big five dimensions of personality theory of organization behaviour as it emerged from decades of research and has gained distinct prominence. Limitations and directions for future research are outlined.
\end{abstract}

Keywords: Knowledge hiding, big five personalities, knowledge sharing

\section{INTRODUCTION}

In a knowledge based economy, capturing, storing, sharing, and using knowledge has gradually become an integral part of most firms' knowledge management strategy. Organizations today want to make sure that they have an effective flow of knowledge to derive the maximum value from the knowledge asset. Transfer and sharing of knowledge are two quintessential of knowledge management. However, employees tend to withhold their knowledge even if they are encouraged and rewarded for doing so (Bock, Zmud, Kim, \& Lee, 2005; Swap, Leonard, Shields, \& Abrams, 2001). Many of the researchers tried to identify that why do people hoard or hide their knowledge (Ford, 2008; Garfield, 2006; Hislop, 2003; Webster et al., 2008) and others have tried to find the reasons as to why this happens and what could be done to promote knowledge sharing in the organizations (DeLong \& Fahey, 2000; Elliott \& O'Dell, 1999; Voelpel, Dous \& Davenport, 2005). In spite of various steps initiated by management, extensive knowledge sharing within organizations still appears to be the exception rather than the rule. Hoarding knowledge and looking guardedly at the knowledge offered by others are natural human tendencies (Davenport \& Prusak 1998). 


\section{LITERATURE REVIEW}

\section{Knowledge sharing}

Knowledge sharing can be referred to as the process of capturing knowledge or moving knowledge from a source unit to a recipient unit (Bircham-Connoly, Corner \& Bowden, 2005). Willem (2003) on the other hand defines KS as exchange of knowledge between two parties in a reciprocal process allowing reshape and sense making of the knowledge in the new context. Today's professionals are confronted with the "information-based, knowledge-driven, serviceintensive economy" (Bartlett \& Ghoshal, 2002). Thus, knowledge is dependent on the individuals in the organization. It has been suggested that organizational knowledge resides in the interactions between individuals which forms the basis of competitive advantage (Argote \& Ingram, 2000; Nonaka, 1991). Knowledge can be classified into tacit and explicit (Nonaka, 1994). Explicit knowledge is defined by Polanyi $(1966,1998)$ as knowledge that is formal, systematic and can be codified into records, databases. Tacit knowledge on the other hand is defined as knowledge that is personal, intangible and embedded in the cognitive minds of people and is obtained through learning and experience (Polanyi, 1966, 1998). Such knowledge can only be transferred by applying it (Choi \& Lee, 2003). This knowledge is therefore more difficult to retain since it is intangible and not available in records. Van den Hooff \& de Ridder (2004) further divide KS into a) knowledge donating - one's own view on his KS willingness b) knowledge receiving -one's view on colleagues KS willingness. This research will explore KS views based on these two dimensions.

Several studies have tried to identify the reasons for people not sharing knowledge. Riege (2005) has classified KS barriers into three broad categories, viz., (a) individual barriers, (b) organizational barriers, and (c) technological barriers. Individual barriers refer to personal barriers such as lack of communication skills, lack of social networks, differences in culture, lack of time, lack of trust, lack of motivation, lack of awareness of the benefit of KS, lack of interaction, fear of not receiving recognition (Riege, 2005; Jain et al., 2007; Wai Ling et al., 2009). Organization barriers are barriers that originate from the firm. Examples of such barriers are lack of rewards, lack of support from top management, ineffective HRM practices, weak organizational structure, inadequate infrastructure, poor organizational culture, office politics, lack of KM/KS strategies, lack of formal and informal avenue to share knowledge, competition between business units, lack of training etc. (Riege, 2005; Jain, et.al, 2007; Wai Ling et.al, 2009). Among the technology barriers highlighted (Riege, 2005) are lack of integration of IT systems/processes, lack of technical support, lack of maintenance of integrated IT systems, people's reluctance to use IT systems and lack of training for familiarization of IT systems and processes.

\section{Knowledge Hiding}

Knowledge hiding is defined as an intentional attempt by an individual to withhold or conceal knowledge that has been requested by another person (Connelly, Zweig, Webster, \& Trougakos, 2011). Connelly et. al. (2011, p. 67) contend that "knowledge hiding is not simply the absence of knowledge sharing. Although a comparison of knowledge hiding and sharing might suggest that individuals either share or hide their knowledge, we suggest that these variables are not the opposites of each other but rather two conceptually distinct constructs." According to one research (Takala \& Urpilainen, 1999), hiding is not always deceptive. Hiding of knowledge could have positive intentions. This behaviour could be possessed to maintain confidentiality or to protect the interests of other parties (Saxe, 1991). Literally, it is not a uniformly negative behaviour. (Lane \& Wegner, 1995). A newspaper survey of approximately 1700 readers suggests that 76 per cent of employees withhold knowledge from their colleagues (The Globe \& Mail, 2006). 
Interestingly, this knowledge hiding construct is comprised of three dimensions (Xenoudaki \& Stafyla, 2012 p. 372): "playing dumb, evasive hiding, and rationalized hiding. An employee using the playing dumb strategy denies having the requested knowledge at his or her disposal and does not share this knowledge, not even in fragments. If an employee communicates false information, or promises to deliver the requested information at a later time while having no intention of doing so whatsoever, then he or she is thought to be operating under the strategy of evasive hiding. These two strategies are likely to have the intention of deception on behalf of the transmitter. During the third strategy, that of rationalized hiding, the hider does not share the requested knowledge (or information), although it does offer the seeker an explanation regarding the reasons for which he or she is unable to deliver, either by expressing a personal weakness to do so, or by transferring the responsibility for hiding that knowledge to a third party (for example, to the supervisor)."

Different researches have assigned different set of reasons behind knowledge hiding behavior within the organizations such as prosocial, instrumental, laziness, etc. (Connelly et al, 2011, Webster et al., 2008). Various perspectives are proposed by one more research including social exchange, norms of secrecy and territorial behaviors (Webster et al., 2008).

\section{Knowledge Hiding vs. Hoarding}

Researchers have attempted to distinguish between knowledge hiding and knowledge hoarding. Knowledge hoarding represent the act of accumulating knowledge that may or may not be shared at a later date (Hislop, 2003). It is more an act of accumulating knowledge with a purpose of making some gain out of it. According to Connelly et al (2011), in contrast to knowledge hoarding, knowledge hiding represents an intentional concealment of knowledge, or an intentional attempt to withhold or conceal knowledge that has been requested by another individual.

According to research by Ford (2008), there might be a behavior, called disengagement, in which individuals neither do share nor actively do hoard/hide their knowledge. However, knowledge hoarding is amassing and protecting of knowledge. Also, hiding is subset of knowledge hoarding. Hiding is basically protecting of knowledge which has been requested whereas hoarding would be the act of not sharing the knowledge (Ford, 2008).The research by Ford identified three different constructs i.e. knowledge sharing, partial knowledge sharing and knowledge hoarding and gave a diagrammatic representation of these three constructs on a continuum (Diagram source- Ford, 2008)-

Figure 1

Knowledge Sharing and Hoarding Continuum
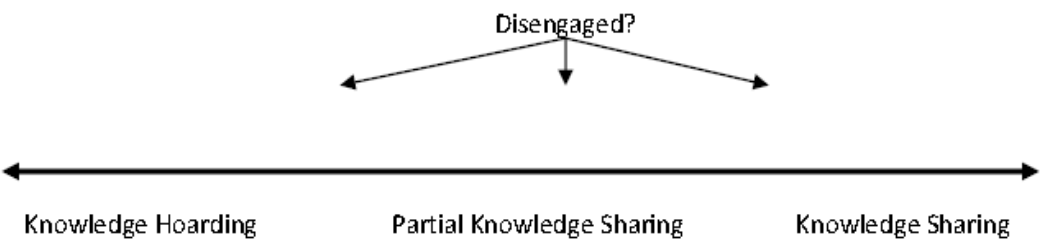
Well, similar to hiding of knowledge, hoarding is not acceptable in the organizations. Employees shouldn't be allowed to hoard knowledge and information. Hoarding takes organizations at risk and hampers the productivity of other workers (Lloyd, 2009). Hence, the concepts of these two may overlap at times, but these are two different constructs in nature.

\section{RESEARCH METHODOLOGY}

Since the research in the field of knowledge hiding is quite novel, there is not much literature available. More than 70 research papers including knowledge hiding and knowledge sharing were culled from various sources such as EBSCO, JSTOR, PROQUEST, Google Scholar etc. However, only those papers were used which were relevant to this study. The focus while doing the literature review on knowledge hiding was on recent papers so that current state of the field could be identified. While doing the literature review on big five personalities, though there were umpteen literature available, only classical papers have been used. The keywords chosen to search the articles/papers were knowledge hiding, hiding, knowledge sharing, sharing, big five personalities, personality dimensions etc. Besides articles and papers, few surveys and newspaper articles were also referred.

\section{BIG 5 PERSONALITY THEORIES: LITERATURE REVIEW AND PROPOSITIONS}

Researchers have been trying to find out the reasons behind variety of individual behaviours such as sharing of knowledge, hoarding or hiding of knowledge etc. Relationship between personality types and learning styles, leadership styles, job satisfaction, job performance etc is well documented. However, the relationship between personality types and knowledge hiding remains unexplored. Earlier researches have shown that individuals who score high on personality inventories tend to be more motivated and enthusiastic about knowledge sharing (Matzler \& Mueller, 2011). Few research studies took help of various personality theories to identify their relationship with knowledge sharing such as the Five Factor Model of Personality (FFM) or the Big Five Personality Model (Matzler \& Mueller, 2011), self-efficacy (Tsai \& Cheng, 2010) and self-esteem (Lee \& Jang, 2010). At the same time, factors such as personal competence and confidence are one of the major requirements for an individual to possess knowledge sharing behaviour (Yaakub et al, 2013).

According to previous researches, individuals who are positive about themselves can face criticism and accept feedback more effectively (Judge \& Mueller, 2011). They are hardly affected by negative evaluations and are risk taking (Lee \& Jang, 2010). "Positive personality traits such as trust and openness are likely to be more influenced by anxiety and tend to withdraw from knowledge sharing behavior. They are afraid of being critiqued and evaluated by others. In our context, it is expected that high core self-evaluations will reduce evaluation apprehension and increase one's motivation in sharing knowledge (Yaakub et al, 2013)".Hence, it is clear that personality plays very important role in knowledge sharing or hoarding of information within organizations. As already discussed, various theories of personalities are used to identify the same but the two majorly used models are the big five personality model (Goldberg, 1990) and Myers-Briggs Type Indicator (MBTI) by Briggs \& Myers (1987). Both the theories have their own pros and cons but big five personality instrument has been used often to assess the personality of individuals (Goldberg \& Saucier, 1995; Mount, Ilies \& Johnson, 2006; Sodiya, Longe, Onashoga, Awodele, \& Omotosho, 2007). The main reason behind this is that it covers most aspects of personality (Robbins, 2003). The big five traits emerged from decades of research and have been celebrated for their ability to simplify an otherwise overwhelming number of traits (Hofsted, 1994; John, 1990; McCrae \& Costa, 1987), their crosscultural capability (McCtae \& Costa, 1997), and their ability to predict behavior. To understand Big Five Personalities dimensions (Extraversion, Emotional Stability, Agreeableness, 
Conscientiousness, and Openness to Experience) and how does it affect the knowledge hiding behaviour, we need to understand each of these dimensions one by one.

\section{Extraversion}

This is the first dimension in big five personality and most frequently this is called as Extraversion or Surgency (Botwin \& Buss, 1989; Digman, \& Chock, 1981; Hogan, 1983; Howarth, 1976; Norman, 1963). The major traits include outgoing, gregarious, assertive, talkative, and energetic. Hogan (1986) considers this dimension as of two components. The first one is 'ambition' that includes initiative, surgency, ambition, and impetuous and the other one is 'sociability' that includes sociable, exhibitionist, and expressive. In a research, extraversion is found to be positively related to the attitude towards knowledge sharing (Teh, Yong, Chong, \& Yew, 2011).

Individuals high in extraversion tend to be sociable (Besser \& Shackelford, 2007). Extraverts are highly enthusiastic, energetic and positive. Studies have suggested that extraverts are likely to have positive emotions and contribute to greater team satisfaction (Watson \& Clark 1984; Barrick, Stewart, Neubert, \& Mount, 1998). As extraverts are emotionally positive and are quite satisfied when working with teams, these individuals might increase knowledge sharing among group members to make their team viable (Teh et al, 2011). On the basis of the traits possessed by extraverts, it is assumed that these individuals would not prefer to hide knowledge. These people would be highly outspoken and enthusiastic about revealing whatever knowledge they have. Hence, it is proposed that-

Proposition 1- A negative relationship exists between extraversion and knowledge hiding behaviour.

\section{Neuroticism}

This is the second dimension of big five personality. According to Barrick and Mount (1991), "Common traits associated with this factor include being anxious, depressed, angry, embarrassed, emotional, worried, and insecure." According to John (1989), "Neuroticism contrasts emotional stability with different negative moods such as anxiety, sadness and nervous tension." It is said that people who are high on neuroticism often express their attitudes toward their co-workers (Lepine \& Dyne, 2001). In a research, neuroticism is found to be positively related to the attitude towards knowledge sharing (Teh et al., 2011). Infact, in one more research, it is found that neuroticism people have poor emotional stability and can easily surrender under anxiety, depression or insecurity (Martínez et al., 2010). Hence, despite of the fact that neurotic people possess negative moods and anxious behaviour, taking previous researches into consideration, it can be assumed that people who are high on neuroticism would not indulge in knowledge hiding behaviour. This presents another set of proposition.

Proposition 2- A negative relationship exists between neuroticism and knowledge hiding behaviour.

\section{Agreeableness}

The third dimension agreeableness is also known as Likability (Conley, 1985; Hakel, 1974; Hogan, 1983; McCrae \& Costa, 1985; Norman, 1963). Researchers have given different names to it such as friendliness (Guilford \& Zimmerman, 1949), social conformity (Fiske, 1949) etc. Characteristics which identify agreeableness are being courteous, flexible, trusting, goodnatured, cooperative, forgiving, soft-hearted, and tolerant. Agreeableness indicates individual's predisposition of being interpersonally pleasant (Besser \& Shackelford 2007). Individuals high in agreeableness are courteous, good-natured, helpful, forgiving, generous, joyful and 
cooperative (Barrick \& Mount, 1991). Characteristics such as sympathetic, altruistic, cooperative, trust worthy and friendly nature are possessed by them which shows that they are willing to share their knowledge in order to make the project successful (Srinivasan, 2009). Due to the characteristics possessed by agreeable individuals, it can be assumed that they would not indulge in knowledge hiding behaviour. Being good natured and liked by people, they would like to be supportive towards others. The proposition proposed is as follows:

Proposition 3- A negative relationship exists between agreeableness and knowledge hiding behaviour.

\section{Conscientiousness}

It is also known as Conscience (Hakel, 1974; John, 1989; McCrae \& Costa, 1985; 1987; Norman, 1963), although it has also been called Conformity or Dependability (Hogan, 1983). This dimension remained contentious among research scholars as some writers (Botwin \& Buss, 1989; Hogan, 1983; John, 1989) have suggested that conscientiousness implies dependability which means being careful, responsible, well thought-out, and planful. Others have added some additional traits to these which say it includes volitional variables such as hardworking, persevering and achievement-oriented. It is assumed that a person high on conscientiousness is more cooperative with others compared to those having lower level of conscientiousness (Lepine \& Dyne, 2001). Conscientiousness possesses traits related to dependability, sense of accomplishment and perseverance (Thomas, Moore \& Scott, 1996). Individuals with high conscientiousness are considered to be more dutiful, dependable, reliable, responsible, organized and hardworking (Barrick \& Mount, 1991). These people are responsible but due to their highly achievement orientation, it could be assumed that these people will indulge in hiding of knowledge to achieve their target, which leads to next proposition:

Proposition 4- A positive relationship exists between conscientiousness and knowledge hiding behaviour.

\section{Openness to Experience}

This is the last dimension and also known as Intellect or Intellectence (Digman \& TakemotoChock, 1981; Hogan, 1983; John, 1989). Openness to Experience (McCrae \& Costa, 1985) or Culture (Hakel, 1974; Norman, 1963), the trait it possesses includes being imaginative, inquisitive, cultured, original, broad-minded, intellectual, and creatively sensitive. This dimension reflects individual's independent, liberal, and daring behaviour. Due to this nature, these individuals intend to gain new knowledge.

In a research, openness to experience is found to have an inverse relationship with the attitude towards knowledge sharing (Teh et al, 2011). Being curious, intelligent, innovative and daring or courageous in nature, it could be assumed that these people would have preference for hiding of knowledge. Hence, the next set of propositions follows:

Proposition 5- A positive relationship exists between openness to experience and knowledge hiding behaviour.

Diagrammatically, the proposed theoretical framework between the big five personality dimensions and knowledge hiding can be shown as follows: 


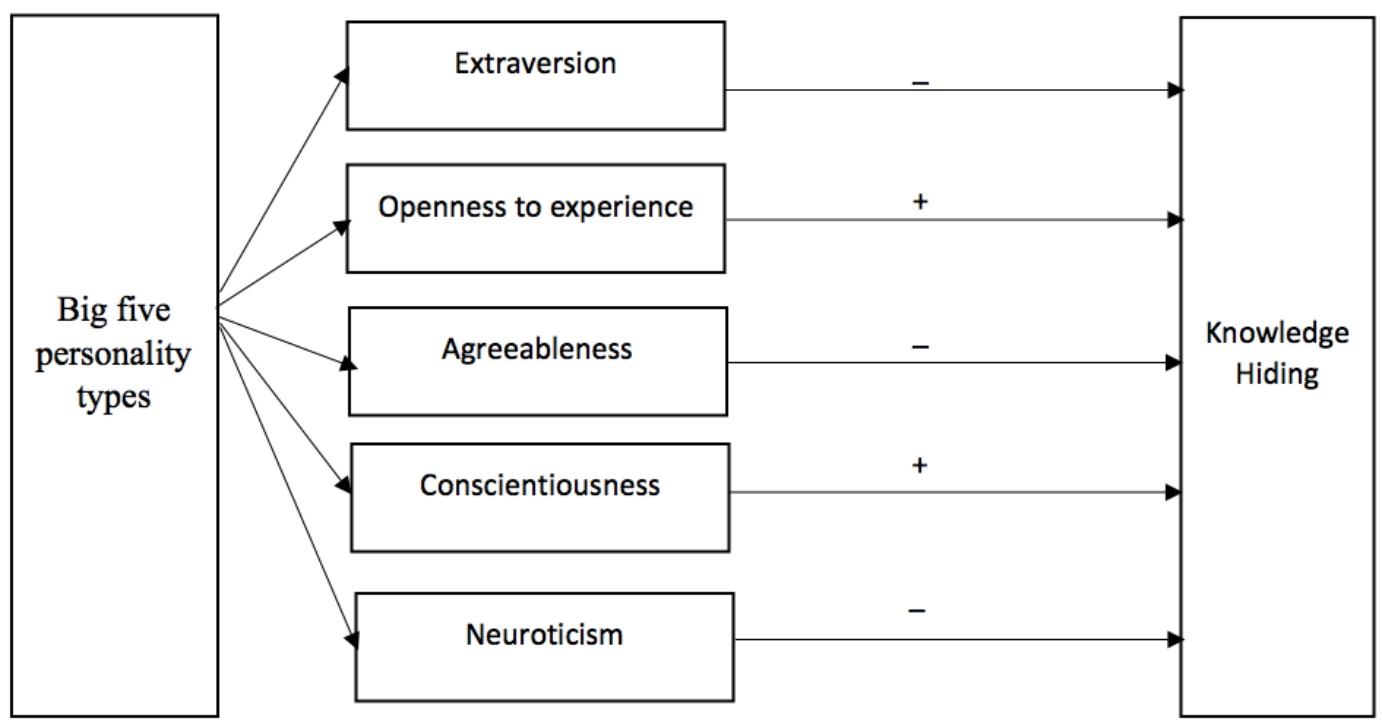

\section{CONCLUSION, LIMITATIONS AND RECOMMENDATIONS FOR FUTURE RESEARCHERS}

The paper makes an attempt to explain a possible relationship that may exist between personality types and knowledge hiding. The relationship needs to be tested empirically. An empirical study by future researchers in different contexts will add to the existing body of knowledge in this field. Such a study will have practical utility for the organizations (such as academic institutions and companies in the IT domain) for whom organizational learning and knowledge management is of great importance. Organizations will be able to design a selection test so that they are able to recruit people with required personality type. The paper makes a unique contribution to theory because this construct has not been examined so far.

It may be noted that the paper has not considered the factors that may have moderating effect on knowledge hiding. It may be worthwhile to see if the culture, leadership, degree of trust etc. may moderate the effect of personality on knowledge hiding. It will also be useful to examine how knowledge hiding affects organizational performance and the kind of organizations that are likely to suffer more because of knowledge hiding.

\section{References}

Argote, L. \& Ingram, P. (2000). Knowledge transfer: A basis for competitive advantage in firms. Organizational Behavior and Human Decision Processes, 82 (1), 150-169.

Barrick, M. R. \& Mount, M. K. (1991). The big five personality dimensions and job performance: a metaanalysis. Personnel psychology, 44, 1-26.

Barrick, M.R., Stewart, G.L., Neubert, M.J. \& Mount, M.K. (1998). Relating member ability and personality to workteam processes and team effectiveness. Journal of Applied Psychology, 83(3), 377-391.

Bartlett, C.A. \& Ghoshal, S. (2002). Managing Across Borders: The Transnational Solution: Harvard Business School Press.

Besser, A. \& Shackelford, T.K. (2007). Mediation of the effects of the big five personality dimensions on negative mood and confirmed affective expectations by perceived situational stress: A quasi-field study of vacationers. Personality and Individual Differences, 42(7), 1333-1346.

Bircham-Connolly, H., Corner, J. and Bowden, S. (2005). An empirical study of the impact of question structure on recipient attitude during knowledge sharing. Electronic Journal of Knowledge Management, 32 (1), 1-10. 
Bock, G.W., Zmud, R.W., Kim, Y. G., \& Lee, J. N. (2005). Behavioral intention formation in knowledge sharing: Examining the roles of extrinsic motivators, social-psychological forces \& organizational climate. MIS Quarterly, 29, 87-112.

Botwin, M.D. \& Buss, D.M. (1989). Structure of act-report data: Is the five-factor model of personality recaptured? Journal of Personality \& Social Psychology, 56, 988-1001.

Briggs, K.C., Myers I.B. \& McCaulley M.H. (1987). The Myers-Briggs Type Indicator (Form G). Consulting Psychologists Press, Palo Alto, CA.

Choi, B. \& Lee, B. (2003). An empirical investigation of KM styles and their effect on corporate performance. Information and Management, 40 (5), 403-417.

Conley J. J. (1985). Longitudinal stability of personality traits: A multi trait-multi method multi occasion analysis. Journal of Personality \& Social Psychology, 49, 1266-1282.

Connelly E. C., Zweig D., Webster J., \& Trougakos P. J. (2011). Knowledge hiding in organizations. Journal of Organizational Behavior, 33, 64-88.

Davenport, Thomas H., \& Prusak, L. (1998). Working Knowledge: How Organizations Manage What They Know. Cambridge, MA: Harvard Business School Press.

DeLong, D.W. \& Fahey, L. (2000). Diagnosing cultural barriers to knowledge management. Academy of Management Executive, 14(4), 113-127

Digman, J. M., Takemoto-Chock, N. K. (1981). Factors in the natural language of personality: Re-Analysis, comparison, and interpretation of six major studies. Multivariate Behavioral Research, I6, 149-170.

Elliott \& O'Dell,C. (1999). Sharing Knowledge \& Best Practices: The Hows and Whys of Tapping Your Organization's Hidden. Health Forum Journal, 42(3), 34.

Fiske D W. (1949). Consistency of the factorial structures of personality ratings from different sources. Journal ofAbnoma1 Social Psychology, 44, 329-344.

Ford, D. P. (2008). Disengagement from knowledge sharing: the alternative explanation for why people are not sharing. Administrative Sciences Association of Canada, 1-24.

Garfield, S. (2006). 10 reasons why people don't share their knowledge, KM Review, 9(2), 10-11.

Goldberg, L. R., \& Saucier, G. (1995). So what do you propose we use instead? Psychological Bulletin, 117, 221-225.

Goldberg, L.R., (1990). An alternative "description of personality": The big-five factor structure. Journal of Personal and Sociological Psychology, 59, 1216-1229.

Guilford, J. P. \& Zimmerman, W. S. (1949). The Guilford-Zimmerman Temperament Survey. Beverly Hills, CA: Sheridan Supply.

Hakel, M. D. (1974). Normative personality factors recovered from ratings of personality descriptors: The beholder's eye. Personnel psychology, 27, 409-421.

Hislop, D. (2003). Linking human resource management and knowledge management via commitment: A review and research agenda. Employee Relations. doi:10.1108/01425450310456479

Hogan, R. (1983). A socio analytic theory of personality. In Page MM. (Ed.), Personality current theory \& research: Nebraska symposium on motivation. Lincoln, NE University of Nebraska Press.

Howarth, E. (1976). Were Cattell's 'personality sphere' factors correctly identified in the first instance? British Journal of Psychology, 67, 213-230.

Jain, K.K, Sandhu, M.M. and Sidhu, G.K (2007), "Knowledge sharing among academic staff: a case study among business schools in Klang Valley, Malaysia", Journal for the Advancemnet of Arts and Science, Vol. 2 January 2007, pp.23-29.

John O. P. (1989). Towards a taxonomy of personality descriptors. In Buss DM, Cantor N (Eds.), Personality psychology: Recent trends and emerging directions. New York: Springer-Verlag. 
John, O. P. (1990). The "Big Five" factor taxonomy: Dimensions of personality in the natural language and in questionnaires. In L. A. Per vin (Ed.) Handbook of personality: Theory and research, 66-100, New York: Guilford Press.

Judge, T. A. \& Mueller, J. D. (2011), “Implications of core self-evaluations for a changing organizational context”, Elsevier Science BV, Human Resource Management Review, 21(4), 331-341.

Lane, J. D., \& Wegner, D. M. (1995). The cognitive consequences of secrecy. Journal of Personality and Social Psychology, 69, 237-253.

Lee E. J., Jang, J. W. (2010). Profiling good Samaritans in online knowledge forums: Effects of affiliative tendency, self-esteem, and public individuation on knowledge sharing. Computers in Human Behavior, 26 (6), 1336-1344.

Lepine, J.A. \& Dyne, L.V. (2001). Voice and cooperative behaviour as contrasting forms of contextual performance: Evidence of differential relationships with big five personality characteristics and cognitive ability. Journal of Applied Psychology, 86(2), 326-336.

Lloyd J. (2009). Manager Must Show Employees That Hoarding Knowledge Won't Bring Job Security. Aspen publishers Inc.

Lorr, M, Manning, T. T. (1978). Higher-order personality factors of the ISI. Multivariate Behavioral Research, 13, 3-7.

Martínez, L.G., A.R. Díaz, G. Licea \& Castro J.R. (2010). Big five patterns for Software Engineering roles using an ANFIS learning approach with RAMSET. Proceedings of the 9th Mexican International Conference on Artificial Intelligence Conference on Advances in Soft Computing: Part II (MICAI' 10), 428-439.

Matzler K. \& Mueller J. (2011), “Antecedents of knowledge sharing - Examining the influence of learning and performance orientation", Elsevier Ltd., Journal of Economic Psychology, 32(3), 317-329.

McCrae, R. R., \& Costa, P. T. (1997). Personality trait structure as a human universal. American Psychology, 52, 509516.

McCrae, R. R., \& Costa, P. T., Jr. (1987). Validation of the five-factor model of personality across instruments and observers. Journal of Personality and Social Psychology, 52, 81-90.

McCrae, RR, \& Costa P. T. (1985). Updating Norman's "adequate taxonomy": Intelligence and personality dimensions in natural language and in questionnaires. Journal of Personality \& Social Psychology, 49,710-721.

Mount, M., Ilies, R, \& Johnson, E. (2006). Relationship of Personality Traits and Counterproductive Work Behaviors: The Mediating Effects of Job Satisfaction. Personnel Psychology, 59, 591-622.

Nonaka, I. (1991). The knowledge-creating company. Harvard Business Review, 69 (6), 96-111.

Nonaka, I. (1994), A dynamic theory of organizational knowledge creation. Organization Science, 5 (1), 14-37.

Norman, W. (1963). Toward an adequate taxonomy of personality attributes: Replicated factor structure in peer nomination personality ratings. Journal of Abnormal \& Social Psychology, 66,576-583.

Polanyi, M. (1966). The Tacit Dimension, Routledge and Kegan Paul: London, UK.Polanyi, M. (1998). The Tacit Dimension, in Prusak, L. (Ed), Knowledge in Organization, Butterworth-Heinemann, Boston, MA

Riege, A. (2005). Three dozen knowledge sharing barriers managers must consider. Journal of Knowledge Management, 9 (3), 18-35.

Robbins, S. P. (2003). Organizational Behaviour. Prentice Hall, New Jersey.

Saxe, L. (1991). Lying: Thoughts of an applied social psychologist. American Psychologist, 46, 409-415.

Sodiya, A.S., H.O.D. Longe, S.A. Onashoga, O. Awodele and L.O. Omotosho (2007). An improved assessment of personality traits in software engineering. Interdisciplinary Journal of Information in Knowledge Management, 2, 163-178.

Srinivasan, S. S. (2009). Performance under requirements uncertainty: A personality perspective. Proceedings of PACIS.

Swap, W., Leonard, D., Shields, M., \& Abrams, L. (2001). Using mentoring and storytelling to transfer knowledge in the workplace. Journal of Management Information Systems, 18, 95-114. 
Takala, T. \& Urpilainen, J. (1999). Managerial work and lying: A conceptual framework and an explorative case study. Journal of Business Ethics, 20, 181-195.

Teh L. P., Yong C.C., Chong W.C. and Yew Y. S. (2011). Do the Big Five Personality Factors affect knowledge sharing behaviour? A study of Malaysian universities. Malaysian Journal of Library \& Information Science, 16(1), 1-16.

The Globe and Mail (2006). The weekly web poll. Friday May 12, 2006, C1.

Thomas, P., Moore, K.S. \& Scott, K.S. (1996). The relationship between self-efficacy for participating in selfmanaged work groups and the big five personality dimensions. Journal of Organizational Behavior, 17(4), 349362.

Tsai, T. M. \& Cheng, C. N. (2010), Programmer perceptions of knowledge-sharing behavior under social cognitive theory, Elsevier Ltd., Expert Systems with Applications, 37(12), 8479-8485.

Van den Hooff, B. \& De Ridder, J.A. (2004), Knowledge sharing in context: The influence of organizational commitment, communication climate and CMC use on knowledge sharing, Journal of Knowledge Management, 8 (6), 117-130.

Voelpel, S. C., Dous, M., \& Davenport, T. H. (2005). Five steps to creating a global knowledge-sharing system: Siemens' ShareNet. Academy of Management Executive, 19(2), 9-23.

Wai Ling, C., Sandhu, M.S. and Jain, K.K. (2009), Knowledge sharing in an American multinational company based in Malaysia. Journal of Workplace Learning, 21 (2), 125-142.

Watson, D. and Clark, L.A. (1984). Negative affectivity: The disposition to experience aversive emotional states. Psychological Bulletin, 96(3), 465-490.

Webster, J., Brown, G., Zweig, D., Connelly, C. E., Brodt, S., \& Sitkin, S. (2008). Beyond knowledge sharing: Knowledge withholding at work. In J. J. Martocchio (Ed.), Research in personnel and human resources management, 27, 1-37. Bradford: Emerald Group Publishing.

Willem, A. (2003). The Role of Organization Specific Integration Mechanisms in Inter-Unit Knowledge Sharing. $\mathrm{PhD}$ Dissertation, Vlerick Leuven Gent Management School, Ghent University, Belgium. Retrieved from http://72.14.203.104/search?q=cache:AwAf_ok1x7UJ:www.ofenhandwerk.com/oklc/pdf

Xenoudaki, C. \& Stafyla A. (2012). Contextual Factors and Personality Traits in the Exhibition of Deceiving and Hiding-Related Behaviors of Employees, in Post Layoff Environments in Greece. International Conference on Enterprise Systems, Accounting and Logistics, 369-384.

Yaakub, K., Shaari, R., Panatik, S. A., Rahman, A. (2013). Towards an Understanding of the Effect of Core SelfEvaluations and Knowledge Sharing Behaviour. International Journal of Applied Psychology, 3(1), 13-18. doi:10.5923/j.ijap.20130301.03 